\title{
Perbedaan Pemahaman Konsep Sistem Koloid Antara Pembelajaran Menggunakan Peta Konsep Dengan Peta Pikiran Pada Siswa Kelas XI MIPA MAN Kota Palangka Raya Tahun Ajaran 2018/2019
}

\author{
Ayu Kristina \\ Program Studi Pendidikan Kimia, Universitas Palangka Raya, Indonesia \\ Email: ayukristina115027@gmail.com
}

Diterima: 13 Nopember 2020; Disetujui: 30 Nopember 2020; Diterbitkan:2 Desember 2020

\begin{abstract}
ABSTRAK
Banyak siswa mengalami kesulitan dalam memahami konsep sistem koloid. Tujuan penelitian ini adalah untuk mendeskripsikan perbedaan pemahaman konsep sistem koloid antara pembelajaran menggunakan peta konsep dengan peta pikiran pada siswa kelas XI MIPA MAN kota Palangka Raya tahun ajaran 2018/2019. Penelitian ini merupakan penelitian kuantitatif. Sampel pada penelitian adalah siswa kelas XI MIPA MAN Kota Palangka Raya sebanyak 52 siswa. Instrumen yang digunakan berupa tes pemahaman konsep (pretes, postes) dan lembar kerja siswa. Hasil analisis data dengan menggunakan uji Mann Whitney menunjukkan bahwa terdapat perbedaan pemahaman konsep sistem koloid antara siswa yang belajar menggunakan peta konsep dengan siswa yang belajar menggunakan peta pikiran. Rata-rata nilai postes siswa kelas peta konsep $(85,40 \%)$ lebih tinggi dari pada rata-rata nilai postes kelas peta pikiran $(71,53 \%)$.
\end{abstract}

Kata Kunci: pemahaman konsep, perbedaan, peta konsep, peta pikiran, sistem koloid

\section{PENDAHULUAN}

Undang-Undang Sistem Pendidikan Nasional (UUSPN) No.20 tahun 2003 menyatakan bahwa pendidikan adalah usaha sadar dan terencana untuk mewujudkan suasana belajar dan proses pembelajaran agar peserta didik secara aktif mengembangkan potensi dirinya untuk memiliki kekuatan spiritual keagamaan, pengendalian diri, kepribadian, kecerdasan, akhlak mulia, serta keterampilan yang diperlukan dirinya, masyarakat, bangsa dan negara. Kegiatan yang tidak terpisahkan dalam proses pembelajaran adalah interaksi antara siswa yang belajar dan guru yang mengajar. Guru sebagai salah satu komponen utama dalam proses pembelajaran yang berperan dalam meningkatkan motivasi siswa untuk lebih aktif. Dominasi guru dalam proses pembelajaran menyebabkan kecenderungan siswa lebih bersifat pasif sehingga mereka lebih banyak menunggu sajian guru daripada mencari dan menemukan sendiri pengetahuan, keterampilan atau sikap yang mereka butuhkan.

Materi sistem koloid seringkali tidak terlalu diminati oleh siswa dalam belajar dan cenderung dianggap tidak penting untuk dipelajari. Siswa beranggapan bahwa mereka dapat menghafal materi ketika akan menghadapi ujian. Akibatnya, aktivitas pembelajaran siswa menjadi pasif. Guru juga cenderung hanya menggunakan metode ceramah untuk menyampaikan materi sistem koloid tersebut kepada siswa dan disampaikan secara sekilas sehingga informasi 
pelajaran yang didapatkan oleh siswa dalam memorinya hanya tersimpan dalam jangka pendek. Salah satu cara atau media pembelajaran yang digunakan untuk menguatkan pengetahuan dan pemahaman peserta didik terhadap bahan-bahan yang telah dibacanya adalah pembelajaran menggunakan peta konsep dan peta pikiran.

Berdasarkan penelitian yang dilakukan oleh Anjelia (2014) terhadap 35 siswa kelas XII IPA-1 SMA Negeri 4 Palangka Raya Tahun Ajaran 2013/2014 dengan mengujikan 2 butir soal yang berkaitan dengan suspensi kasar, larutan sejati, dan koloid. Soal observasi yang diujikan adalah tentang memberikan pengertian suspensi kasar, larutan sejati, dan koloid. Hasil penelitian menemukan bahwa 30 siswa cenderung mengalami kesulitan dalam memberikan pengertian suspensi kasar, larutan sejati, dan koloid.

Karakteristik konsep-konsep pada materi sistem koloid adalah pengetahuan yang berjenis konseptual. Syarat dari pengetahuan konseptual adalah belajar dari fakta dan ide-ide yang menyatakan hubungan antara keduanya. Ranah pengetahuan konseptual berorientasi pada pengetahuan tentang prinsip dan generalisasi dan juga pengetahuan tentang teori.

Karakteristik materi seperti ini membuat penggunaan pembelajaran dengan menggunakan alur berpikir peta konsep dan peta pikiran lebih tepat untuk dijadikan sebagai media pembelajaran dalam belajar sistem koloid. Alur berpikir peta konsep adalah suatu metode pembelajaran yang meminta siswa untuk mengaitkan konsep-konsep yang saling berhubungan dalam bentuk gambar atau diagram dan memiliki hubungan yang mengaitkan antara konsep-konsep tersebut. Alur berpikir peta pikiran adalah suatu metode untuk mengelola informasi secara keseluruhan melalui pemetaan peta pikiran berbentuk percabangan yang dituangkan langsung ke dalam media tulis (baik kertas maupun digital).

Belajar menggunakan pembelajaran dengan alur peta konsep dan peta pikiran diduga memberikan perbedaan terhadap pemahaman konsep siswa, sehingga berdasarkan uraian-uraian yang telah dijelaskan penting untuk dilakukan penelitian dengan judul "perbedaan pemahaman konsep sistem koloid antara pembelajaran menggunakan peta konsep dengan peta pikiran pada siswa kelas XI MIPA MAN kota Palangka Raya tahun ajaran 2018/2019”.

\section{METODE PENELITIAN}

Jenis penelitian ini adalah penelitian eksperimen. Penelitian ini akan mencoba memberikan perlakuan terhadap sampel dan mengidentifikasi apakah perlakuan tersebut memberikan pengaruh terhadap sampel. Pada penelitian ini sampel kelas akan diberikan perlakuan dengan cara belajar menggunakan peta konsep dan peta pikiran. Hasil dari perlakuan ini akan dianalisis apakah terdapat perbedaan terhadap pemahaman siswa hasil pembelajaran dengan cara belajar menggunakan peta konsep dan peta pikiran. Subjek penelitian ini adalah siswa kelas XI MIPA MAN Kota Palangka Raya Tahun Ajaran 2018/2019.

Teknik pengumpulan data dan instrumen yang digunakan disajikan pada Tabel 1 . 
Tabel 1. Teknik Pengumpulan Data dan Instrumen

\begin{tabular}{|c|c|c|}
\hline Data yang diperlukan & Cara Pengumpulan Data & Instrumen \\
\hline $\begin{array}{l}\text { Pemahamankonsep awal } \\
\text { siswa }\end{array}$ & $\begin{array}{l}\text { Memberikan tes tertulis (Pretes) } \\
\text { kepada semua siswa untuk } \\
\text { dikerjakansecara individudan } \\
\text { tanpa melihat bukukimia }\end{array}$ & $\begin{array}{l}\text { Soal tes pemahaman } \\
\text { konsep (Pretes) }\end{array}$ \\
\hline $\begin{array}{l}\text { Pemahaman konsep materi } \\
\text { sistemkoloid saat } \\
\text { pembelajaran }\end{array}$ & $\begin{array}{l}\text { Memberikan lembarkerja peta } \\
\text { konsep kepada kelas yang } \\
\text { mendapatkan perlakuan dengan } \\
\text { menggunakan cara belajar peta } \\
\text { konsep untuk dikerjakansecara } \\
\text { mandiri denganbantuan } \\
\text { menggunakan handout dan } \\
\text { memberikanperlakuan } \\
\text { pembuatan peta pikiran kepada } \\
\text { kelas yangmendapatkan } \\
\text { perlakuan dengan menggunakan } \\
\text { cara belajar peta pikiran untuk } \\
\text { dikerjakansecaramandiri dengan } \\
\text { bantuanmenggunakan } h a n d ~ o u t \\
\text { lembar tuntuman langkah-langkah } \\
\text { membuatpeta pikirandan contoh } \\
\text { peta pikiran }\end{array}$ & $\begin{array}{l}\text { Lembarkerja petakonsep } \\
\text { danlembarkertas HVS } \\
\text { kosonguntuk membuat } \\
\text { peta pikiran }\end{array}$ \\
\hline $\begin{array}{l}\text { Pemahamankonsep siswa } \\
\text { setelah pembelajaran }\end{array}$ & $\begin{array}{l}\text { Memberikan tes tertulis (Postes) } \\
\text { kepada semua siswa untuk } \\
\text { dikerjakansecaraindividudan } \\
\text { tanpa melihat bukukimia }\end{array}$ & $\begin{array}{l}\text { Soal tes pemahaman } \\
\text { konsep (Postes) }\end{array}$ \\
\hline
\end{tabular}

Teknik pengolahan data pada hasil pretes dan postes siswa dilakukan dengan beberapa langkah sebagai berikut:

a. Memberikan skor terhadap jawaban siswa menggunakan pedoman penskoran sebagaimana dapat dilihat pada lampiran 5 .

b. Menentukan nilai yang diperoleh di konversikan ke dalam bentuk persentase pemahaman dengan cara sebagai berikut:

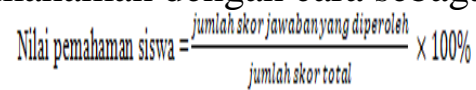

c. Menentukan rata-rata pemahaman konsep (pretes dan postes) dihitung menggunakan rumus: $\frac{\text { Jumlah nilai seluruh sampel }}{\text { Jumlah sampel }}$

d. Menentukan perhitungan sebaran data pretes dan postes pada peta konsep dan peta pikiran menggunakan beberapa rumus sebagai berikut:

1) Menentukan nilai range $\left(X_{\operatorname{maks}}-X_{\min }\right)$ dari nilai range dapat ditentukan banyak kelas dengan melihat satu angka pertama pada nilai range.

2) Mnentukan nterval kelas/panjang kelas adalah selisih antara data terbesar dengan data terkecil dibagi dengan banyaknya kelas, dapat dirumuskan:

$$
\mathrm{p}=\frac{\text { Range }}{\text { Banyaknya Kelas }}
$$

3) Untuk menentukan batas kelas dapat dilakukan dengan cara mengurangi angka 0,5 dari ujung bawah/limit bawah kelas pertama.

4) Frekuensi adalah banyaknya kejadian (nilai) yang muncul pada selang kelas tertentu. 
5) Frekuensi Kumulatif (FK) adalah jumlah dari nilai pertama pada frekuensi ditambah dengan nilai pertama pada frekuensi kumulatif, nilai pertama frekuensi kumulatif disamakan dengan nilai pertama frekuensi.

6) Menentukan F\% dengan cara nilai pada setiap frekuensi dibagi dengan jumlah sampel dan dikalikan dengan 100.

7) Menentukan FK\% dihitung dengan cara nilai pada setiap frekuensi kumulatif dibagi dengan jumlah sampel dan dikalikan dengan 100.

\section{HASIL PENELITIAN DAN PEMBAHASAN}

Setiap jawaban pretes dan postes siswa kelas peta konsep dan kelas peta pikiran diperiksa kemudian diberikan skor sesuai kriteria penskoran yang terdapat pada rubrik penilaian. Tabel 2 menunjukkan persentase pemahaman konsep siswa untuk hasil pretes dan postes pada kelas peta konsep dan kelas peta pikiran. Berdasarkan hasil Tabel 2 dapat dilihat bahwa kemampuan yang dimiliki oleh siswa pada kelas peta konsep dan kelas peta pikiran tidak berbeda secara signifikan. Hal ini dapat dilihat pada hasil nilai rata-rata hasil pretes kelas peta konsep dan kelas peta pikiran setelah dilakukan pembelajaran langsung. Skor pretes dan postes siswa kelas peta konsep dan kelas peta pikiran ditunjukkan pada Tabel 2.

Nilai rata-rata hasil pretes dan postes kelas peta konsep dan kelas peta pikiran setelah dilakukan pembelajaran peta konsep dan peta pikiran disajikan pada Tabel 2.

Rata-rata hasil pretes pada kelas peta konsep sebesar 29,54 sedangkan pada kelas peta pikiran sebesar 29,45. Setelah kedua kelas diberikan cara belajar yang berbeda, yaitu pada kelas peta konsep diberikan cara belajar menggunakan peta konsep dan kelas peta pikiran diberikan cara belajar menggunakan peta pikiran. Nilai rata-rata pada kedua kelas tersebut mengalami peningkatan yaitu pada kelas peta konsep sebesar 85,40 dan kelas peta pikiran sebesar 71,15.

\section{Sebaran Data Pretes Kelas Peta Konsep}

Nilai pretes kelas peta konsep diperoleh dari tes kemampuan awal yang diberikan sebelum adanya perlakuan dengan menggunakan peta konsep. Keseluruhan siswa berjumlah 26 orang. Nilai pretes kelas peta konsep memiliki nilai terendah 11,36 dan nilai tertinggi 40,91, dengan rentang data (R) 36,36, panjang kelas interval sebesar 7, interval kelas sebesar 5, rata-rata sebesar 29,54, varians $\left(S^{2}\right) 67,35$, dan standar deviasi sebesar 8,20. Distribusi frekuensi pretes kelas peta konsep dapat dilihat pada Tabel 3.

Tabel 3 menunjukkan distribusi frekuensi kemampuan awal (pretes) kelas peta konsep bahwa sebanyak 7 siswa atau 26,92\% siswa mendapat nilai di bawah rata-rata dan sebanyak 19 siswa atau 73,08\% siswa mendapat nilai di atas ratarata.

\section{Sebaran Data Pretes Kelas Peta Pikiran}

Nilai pretes kelas peta pikiran diperoleh dari tes kemampuan awal yang diberikan sebelum adanya perlakuan dengan menggunakan peta pikiran. Keseluruhan siswa berjumlah 26 orang. Nilai kemampuan awal kelas peta pikiran memiliki nilai terendah 6,81 dan nilai tertinggi 50, dengan rentang data (R) 47,72; panjang kelas sebesar 9; interval kelas sebesar 5; rata-rata nilai sebesar 29,45; 
varian $\left(S^{2}\right)$ 156,39 dan standar deviasi sebesar 12,22. Distribusi frekuensi pretes kelas peta pikiran dapat dilihat pada Tabel 4.

Tabel 2. Rata-rata Data Hasil Pretes dan Postes Kelas Peta Konsep dan Peta Pikiran

\begin{tabular}{|c|c|c|c|c|c|}
\hline \multirow[t]{2}{*}{ Kode Siswa } & \multicolumn{2}{|c|}{ Kelas Peta Konsep } & \multirow[t]{2}{*}{ Kode Siswa } & \multicolumn{2}{|c|}{ Kelas Peta Pikiran } \\
\hline & Skor Pretes & Skor Postes & & Skor Pretes & Skor Postes \\
\hline EI-01 & 40,91 & 86,36 & EII-01 & 54,55 & 72,73 \\
\hline EI-02 & 47,73 & 84,09 & EII-02 & 38,64 & 72,73 \\
\hline EI-03 & 36,36 & 100 & EII-03 & 36,36 & 72,73 \\
\hline EI-04 & 34,09 & 95,45 & EII-04 & 15,91 & 81,82 \\
\hline EI-05 & 31,82 & 72,73 & EII-05 & 40,91 & 72,73 \\
\hline EI-06 & 40,91 & 100 & EII-06 & 29,55 & 65,91 \\
\hline EI-07 & 36,36 & 95,45 & EII-07 & 15,91 & 77,27 \\
\hline EI-08 & 18,18 & 72,73 & EII-08 & 31,82 & 65,91 \\
\hline EI-09 & 25 & 75 & EII-09 & 22,73 & 75 \\
\hline EI-10 & 29,55 & 93,18 & EII-10 & 6,81 & 45,45 \\
\hline EI-11 & 29,55 & 90,91 & EII-11 & 34,09 & 63,64 \\
\hline EI-12 & 31,82 & 81,82 & EII-12 & 11,36 & 59,09 \\
\hline EI-13 & 29,55 & 95,45 & EII-13 & 34,09 & 88,64 \\
\hline EI-14 & 31,82 & 81,82 & EII-14 & 36,36 & 75 \\
\hline EI-15 & 27,27 & 86,36 & EII-15 & 47,73 & 79,55 \\
\hline EI-16 & 38,64 & 65,91 & EII-16 & 15,91 & 59,09 \\
\hline EI-17 & 20,45 & 84,09 & EII-17 & 34,09 & 72,73 \\
\hline EI-18 & 22,73 & 81,82 & EII-18 & 29,55 & 70,45 \\
\hline EI-19 & 29,55 & 86,36 & EII-19 & 50 & 84,09 \\
\hline EI-20 & 20,45 & 81,82 & EII-20 & 38,64 & 75 \\
\hline EI-21 & 11,36 & 79,55 & EII-21 & 29,55 & 79,55 \\
\hline EI-22 & 20,45 & 84,09 & EII-22 & 18,18 & 75 \\
\hline EI-23 & 34,09 & 84,09 & EII-23 & 15,91 & 59,09 \\
\hline EI-24 & 20,45 & 84,09 & EII-24 & 15,91 & 75 \\
\hline EI-25 & 29,55 & 81,82 & EII-25 & 22,73 & 54,55 \\
\hline EI-26 & 29,55 & 95,45 & EII-26 & 38,64 & 77,27 \\
\hline Rata-rata & 29,54 & 85,40 & Rata-rata & 29,45 & 71,15 \\
\hline SD & 8,20 & 8,58 & SD & 12,22 & 9,74 \\
\hline
\end{tabular}

Tabel 3. Distribusi Frekuensi Pretes Kelas Peta Konsep

\begin{tabular}{|c|c|c|c|c|c|c|}
\hline $\begin{array}{c}\text { Banyak } \\
\text { Kelas }\end{array}$ & Interval & $\begin{array}{l}\text { Batas } \\
\text { Kelas }\end{array}$ & F & FK & $\mathrm{F} \%$ & FK $\%$ \\
\hline$T$ & $11,36-17,36$ & 14,36 & $T$ & $T$ & 3,84 & 3,84 \\
\hline 2 & $18,36-24,36$ & 21,36 & 6 & 7 & 23,07 & 26,92 \\
\hline 3 & $25,36-31,36$ & 28,36 & 11 & 18 & 42,30 & 69,23 \\
\hline 4 & $32,36-38,36$ & 35,36 & 5 & 23 & 19,23 & 88,46 \\
\hline 5 & $39,36-45,36$ & 42,36 & 2 & 25 & 7,69 & 96,15 \\
\hline 6 & $46,36-52,36$ & 49,36 & 1 & 26 & 3,84 & 100 \\
\hline & \multirow{2}{*}{$\Sigma$} & & 26 & & 100 & \\
\hline & & & & & & \\
\hline
\end{tabular}

Keterangan; $F=$ Frekuensi

FK = Frekuensi Kumulatif 
Tabel 4. Distribusi Frekuensi Pretes Kelas Peta Pikiran

\begin{tabular}{|c|c|c|c|c|c|c|}
\hline $\begin{array}{c}\text { Banyak } \\
\text { Kelas }\end{array}$ & Interval & $\begin{array}{l}\text { Batas } \\
\text { Kelas }\end{array}$ & F & FK & $\mathrm{F} \%$ & FK $\%$ \\
\hline 1 & $6-14$ & 10 & 2 & 2 & 7,69 & 7,69 \\
\hline 2 & $15-23$ & 19 & 8 & 10 & 30,76 & 38,46 \\
\hline 3 & $24-32$ & 28 & 4 & 14 & 15,38 & 53,84 \\
\hline 4 & $33-41$ & 37 & 9 & 23 & 34,61 & 88,46 \\
\hline 5 & $42-50$ & 46 & 2 & 25 & 7,69 & 96,15 \\
\hline \multirow[t]{2}{*}{6} & 51.59 & 55 & 1 & 26 & 3,84 & 100 \\
\hline & $\Sigma$ & & 26 & & 100 & \\
\hline & & & & & & \\
\hline
\end{tabular}

Keterangan; $F=$ Frekuensi FK $=$ Frekuensi Kumulatif

\section{Sebaran Data Postes Kelas Peta Konsep}

Nilai postes pada kelas peta konsep didapatkan setelah proses pembelajaran langsung yang dilanjutkan dengan memberikan perlakuan dengan menggunakan peta konsep. Terdapat 26 siswa yang mengikuti tes akhir pada kelas peta konsep dengan nilai terendah 65,91 dan nilai tertinggi 100 , dengan rentang data (R) 34,09, panjang kelas interval sebesar 6, interval kelas sebesar 5, rata-rata nilai sebesar 85,40, varians $\left(S^{2}\right) 73,62$ dan standar deviasi sebesar 8,58. Distribusi frekuensi Postes kelas peta konsep dapat dilihat pada Tabel 5.

Tabel 5. Distribusi Frekuensi Postes Kelas Peta Konsep

\begin{tabular}{|c|c|c|c|c|c|c|}
\hline $\begin{array}{c}\text { Banyak } \\
\text { Kelas }\end{array}$ & Interval & $\begin{array}{l}\text { Batas } \\
\text { Kelas }\end{array}$ & $\mathbf{F}$ & FK & $\mathbf{F} \%$ & FK $\%$ \\
\hline 1 & $65-70$ & 70,5 & 1 & 1 & 3,84 & 3,84 \\
\hline 2 & $71-76$ & 76,5 & 3 & 4 & 11,53 & 15,38 \\
\hline 3 & $77-82$ & 82,5 & 6 & 10 & 23,07 & 38,46 \\
\hline 4 & $83-88$ & 88,5 & 8 & 18 & 30,76 & 69,23 \\
\hline 5 & $89-94$ & 94,5 & 2 & 20 & 7,69 & 76,92 \\
\hline \multirow[t]{2}{*}{6} & $95-100$ & 100,5 & 6 & 26 & 23,07 & 100 \\
\hline & $\Sigma$ & & 26 & & 100 & \\
\hline & & & & & & \\
\hline
\end{tabular}

Keterangan: $\mathrm{F}=$ Frekuensi

FK = Frekuensi Kumulatif

\section{Sebaran Data Postes Kelas Peta Pikiran}

Nilai postes pada kelas peta pikiran didapatkan setelah proses pembelajaran langsung yang dilanjutkan dengan memberikan perlakuan dengan menggunakan peta pikiran. Terdapat 26 siswa yang mengikuti tes akhir pada kelas peta pikiran dengan nilai terendah 45,45 dan nilai tertinggi 88,64 , dengan rentang data (R) 43,19, panjang kelas interval sebesar 8, interval kelas sebesar 5, rata-rata nilai sebesar 71,15, varians $\left(\mathrm{S}^{2}\right)$ 94,94 dan standar deviasi sebesar 9,74. Distribusi frekuensi postes kelas peta pikiran dapat dilihat pada Tabel 6. 


\section{Tabel 6. Distribusi Frekuensi Postes Kelas Peta Pikiran}

\begin{tabular}{|c|c|c|c|c|c|c|}
\hline $\begin{array}{c}\text { Banyak } \\
\text { Kelas }\end{array}$ & Interval & $\begin{array}{l}\text { Batas } \\
\text { Kelas }\end{array}$ & F & FK & $\mathrm{F} \%$ & FK $\%$ \\
\hline 1 & $45-52$ & 48,5 & 1 & 1 & 3,84 & 3,84 \\
\hline 2 & $53-60$ & 56,5 & 4 & 5 & 15,38 & 19,23 \\
\hline 3 & 61.68 & 64,5 & 3 & 8 & 11,53 & 30,76 \\
\hline 4 & $69-76$ & 72,5 & 11 & 19 & 42,30 & 73,07 \\
\hline 5 & 77.84 & 80,5 & 6 & 25 & 23,07 & 96,15 \\
\hline 6 & $85-92$ & 88,5 & 1 & 26 & 3,84 & 100 \\
\hline \multirow[t]{2}{*}{7} & $93-100$ & 96,5 & 0 & & 0 & 0 \\
\hline & $\Gamma$ & & 26 & & 100 & \\
\hline & & & & & & \\
\hline
\end{tabular}

Keterangan; $F=$ Frekuensi

FK = Frekuensi Kumulatif

Tabel 6 menunjukkan distribusi frekuensi kemampuan akhir (postes) kelas peta pikiran bahwa sebanyak 8 siswa atau $30,76 \%$ siswa mendapat nilai dibawah rata-rata dan sebanyak 18 siswa atau 69,24\% siswa mendapat nilai di atas ratarata.

\section{PEMBAHASAN}

Hasil pembelajaran kelas peta konsep jauh lebih baik daripada hasil pembelajaran kelas peta pikiran, hal tersebut dikarenakan bahwa pada kelas peta konsep siswa belajar menggunakan kerangka peta konsep yang sudah disiapkan oleh guru sedangkan pada kelas peta pikiran kerangka pikiran tidak dapat disiapkan tetapi diberikan mekanisme pembuatan peta pikiran dan contoh peta pikiran untuk mempermudah siswa dalam membuat peta pikiran. Data pemahaman konsep siswa menyimpulkan bahwa belajar dengan menggunakan kerangka peta konsep yang telah disiapkan oleh guru lebih sistematis dan komprehensif dibandingkan belajar dengan membuat peta pikiran.

Hasil analisis pada Tabel 2 menunjukan bahwa rata-rata nilai pretes kelas peta konsep dan kelas peta pikiran adalah 29,54 dan 29,45, rata-rata nilai postes kelas peta konsep dan kelas peta pikiran adalah 85,40 dan 71,15. Rata-rata nilai postes kelas peta konsep dan kelas peta pikiran adalah berbeda, di mana rata-rata nilai postes pada kelas peta konsep lebih tinggi daripada kelas peta pikiran.

\section{Mengelompokkan campuran (koloid, suspensi kasar, serta larutan sejati) (Indikator-1)}

Pemahaman konsep siswa dalam mengelompokkan campuran (koloid, suspensi kasar, serta larutan sejati) ditelusuri menggunakan butir soal nomor 1 . Jawaban siswa pada butir soal nomor 1 diberikan skor menggunakan rubik penskoran sebagaimana dideskripsikan pada Tabel 7.

Berdasarkan hasil analisis data pretes dan postes siswa, maka didapat perubahan skor jawaban pada butir soal 1 untuk kelas peta konsep dan kelas peta pikiran. Sebaran Perubahan skor jawaban disajikan pada Tabel 8. 


\section{Tabel 7. Deskripsi Pemahaman dan Skor Jawaban pada Butir Soal 1}

\begin{tabular}{|c|c|}
\hline Deskripsi Pemahaman & Skor \\
\hline \multicolumn{2}{|l|}{ Tujuan l: Siswa dapat menggolongkan contoh-contoh koloid dari sejumlah campuran } \\
\hline Tidak ada jawaban atau jawaban tidak relevan/salah & 0 \\
\hline Dapat menuliskan satu contoh koloid dari sejumlah contoh campuran & 1 \\
\hline Dapat menuliskan dua contoh koloid dari sejumlah contoh campuran & 2 \\
\hline Dapat menuliskan dua contoh koloid dari sejumlah contoh campuran & 3 \\
\hline $\begin{array}{l}\text { Tujuan 2: Siswa dapat menggolongkan contoh-contoh suspensi kasar dari } \\
\text { sejumlah campuran }\end{array}$ & \\
\hline Tidak ada jawaban atau jawaban tidak relevan/salah & 0 \\
\hline Dapat menuliskan satu contoh suspensi kasar dari sejumlah contoh campuran & 1 \\
\hline Dapat menuliskan dua contoh suspensi kasar dari sejumlah contoh campuran & 2 \\
\hline Dapat menuliskan tiga contoh suspensi kasar dari sejumlah contoh campuran & 3 \\
\hline $\begin{array}{l}\text { Tujuan 3: Siswa dapatmenggolongkan contoh-contoh larutan sejati dari } \\
\text { sejumlah campuran }\end{array}$ & \\
\hline Tidak ada jawaban atau jawaban tidak relevan/salah & 0 \\
\hline Dapat menuliskan satu contoh lanutan sejati dari sejumlah contoh campuran & 1 \\
\hline Dapat menuliskan dua contoh lanutan sejati dari sejumlah contoh campuran & 2 \\
\hline Dapat menuliskan tiga contoh larutan sejati dari sejumlah contoh campuran & 3 \\
\hline
\end{tabular}

Tabel 8. Sebaran Perubahan Skor Jawaban Siswa pada Pretes dan Postes untuk Kelas Peta Konsep dan Kelas Peta Pikiran

\begin{tabular}{|c|c|c|c|c|}
\hline & $\begin{array}{l}\text { E Siswa Kelas } \\
\text { Peta Konsep }\end{array}$ & $\begin{array}{l}\text { E Siswa Kelas } \\
\text { Peta Pikiran }\end{array}$ & $\begin{array}{l}\text { E Siswa Kelas } \\
\text { Peta Konsep }\end{array}$ & $\begin{array}{l}\text { E Siswa Kelas } \\
\text { Peta Pikiran }\end{array}$ \\
\hline 0 & 2 & 10 & - & - \\
\hline 1 & 1 & 2 & - & - \\
\hline 2 & 2 & 2 & - & - \\
\hline 3 & 6 & 2 & - & 1 \\
\hline 4 & 6 & 2 & - & - \\
\hline 5 & 5 & 1 & - & 1 \\
\hline 6 & 1 & - & - & 2 \\
\hline 7 & 1 & 5 & 5 & 5 \\
\hline 8 & 2 & 2 & 11 & 7 \\
\hline 9 & - & - & 10 & 10 \\
\hline
\end{tabular}

Perolehan skor dominan pada kelas peta konsep dan kelas peta pikiran menunjukan bahwa setelah belajar menggunakan peta konsep dan peta pikiran siswa memiliki pemahaman konsep untuk mengelompokkan campuran (koloid, suspensi kasar, serta larutan sejati).

Tabel 9. Perubahan Rata-rata Skor Pretes dan Postes Kelas Peta Konsep dan Kelas Peta Pikiran pada Konsep Mengelompokkan Campuran (Koloid, Suspensi kasar, serta Larutan Sejati)

\begin{tabular}{|c|c|c|}
\hline \multirow{2}{*}{ Kelas } & \multicolumn{2}{|c|}{ Rata-rata nilai } \\
\cline { 2 - 3 } & Pretes & Postes \\
\hline Peta konsep & 43,16 & 91,02 \\
\hline Peta pilirnn & 32,47 & 85,89 \\
\hline
\end{tabular}

Data tersebut menyimpulkan bahwa pemahaman konsep siswa kelas peta konsep dan kelas peta pikiran pada konsep mengelompokkan campuran (koloid, suspensi kasar, serta larutan sejati) berbeda. 


\section{Membedakan Koloid, Suspensi Kasar, serta Larutan Sejati Berdasarkan Ciri-Ciri Yang Dapat Diamati (Indikator-2)}

Pemahaman konsep siswa dalam membedakan koloid, suspensi kasar, serta larutan sejati berdasarkan ciri-ciri yang dapat diamati ditelusuri menggunakan butir soal nomor 2. Jawaban siswa pada butir soal nomor 2 diberikan skor menggunakan rubrik penskoran sebagaimana dideskripsikan pada Tabel 10.

\section{Tabel 10. Deskripsi Pemahaman dan Skor Jawaban pada Butir Soal 2}

\begin{tabular}{|c|c|}
\hline $\begin{array}{l}\text { Deskripsi Pemahaman } \\
\end{array}$ & Skor \\
\hline \multicolumn{2}{|l|}{ Tujuan l: Siswa dapat menuliskan ciri-ciri larutan sejati } \\
\hline Tidak ada jawaban atau jawaban tidak relevan/salah & 0 \\
\hline Dapat menuliskan satu ciri larutan sejati & 1 \\
\hline Dapat menuliskan dua ciri larutan sejati & 2 \\
\hline Dapat menuliskan tiga ciri lanutan sejati & 3 \\
\hline Dapat menuliskan empat ciri larutan sejati & 4 \\
\hline Dapat menuliskan lima ciri lanutan sejati & 5 \\
\hline \multicolumn{2}{|l|}{ Tujuan 2: Siswa dapat menuliskan ciri-ciri koloid } \\
\hline Tidak ada jawaban atau jawaban tidak relevan/salah & 0 \\
\hline Dapat menuliskan satu ciri koloid & 1 \\
\hline Dapat menuliskan dua ciri koloid & 2 \\
\hline Dapat menuliskan tiga ciri koloid & 3 \\
\hline Dapat menuliskan empat ciri koloid & 4 \\
\hline Dapat menuliskan lima ciri koloid & 5 \\
\hline \multicolumn{2}{|l|}{ Tujuan 3 : Siswa dapatmenuliskan ciri-ciri suspensi kasar } \\
\hline Tidak ada jawaban atau jawaban tidak relevan/salah & 0 \\
\hline Dapat menuliskan satu ciri suspensi kasar & 1 \\
\hline Dapat menuliskan dua ciri suspensi kasar & 2 \\
\hline Dapat menuliskan tiga cir suspensi kasar & 3 \\
\hline Dapat menuliskan empat ciri suspensi kasar & 4 \\
\hline Dapat menuliskan lima ciri suspensi kasar & 5 \\
\hline
\end{tabular}

Berdasarkan hasil analisis data pretes dan postes siswa didapatkan perubahan skor jawaban pada butir soal 2 untuk kelas peta konsep dan kelas peta pikiran. Sebaran Perubahan skor jawaban disajikan pada Tabel 11.

Perolehan skor dominan skor 13 menunjukan bahwa setelah belajar menggunakan peta konsep dan peta pikiran, siswa memiliki pemahaman konsep yang cukup baik untuk membedakan koloid, suspensi kasar, serta larutan sejati berdasarkan ciri-ciri yang dapat diamati.

Rata-rata nilai postes kelas peta konsep adalah sebesar 84,10 sedangkan nilai postes kelas peta pikiran adalah sebesar 84,02, sehingga dapat dilihat bahwa hasil nilai postes kelas peta konsep dan peta pikiran relatif sama.

\section{Menuliskan Komponen Koloid Fasa Terdispersi dan Medium Pendispersi (Indikator-3)}

Pemahaman konsep siswa dalam menuliskan komponen koloid fasa terdispersi dan medium pendispersi ditelusuri menggunakan butir soal nomor 3 . Jawaban siswa pada butir soal nomor 3 diberikan skor menggunakan rubrik penskoran sebagaimana dideskripsikan pada Tabel 13. 
Tabel 11. Sebaran Perubahan Skor Jawaban Siswa pada Pretes dan Postes untuk Kelas Peta Konsep dan Kelas Peta Pikiran

\begin{tabular}{|c|c|c|c|c|}
\hline \multirow[b]{2}{*}{ Skor } & \multicolumn{2}{|c|}{ Pretes } & \multicolumn{2}{|c|}{ Postes } \\
\hline & $\begin{array}{l}\text { E Siswa Kelas } \\
\text { Peta Konsep }\end{array}$ & $\begin{array}{l}\text { E Siswa Kelas } \\
\text { Peta Pikiran }\end{array}$ & $\begin{array}{l}\text { E Siswa Kelas } \\
\text { Peta Konsep }\end{array}$ & $\begin{array}{l}\text { E Siswa Kelas } \\
\text { Peta Pikiran }\end{array}$ \\
\hline 0 & - & 2 & - & - \\
\hline 1 & - & - & - & - \\
\hline 2 & - & 1 & - & - \\
\hline 3 & 1 & 1 & - & - \\
\hline 4 & 3 & - & - & - \\
\hline 5 & 3 & - & - & - \\
\hline 6 & 3 & - & - & - \\
\hline 7 & 1 & 3 & - & - \\
\hline 8 & 4 & 2 & - & - \\
\hline 9 & 2 & - & - & 2 \\
\hline 10 & 5 & 5 & 3 & 2 \\
\hline 11 & 1 & - & 2 & 1 \\
\hline 12 & 1 & 3 & 7 & 4 \\
\hline 13 & 1 & 7 & 8 & 8 \\
\hline 14 & - & 2 & 2 & 6 \\
\hline 15 & 1 & - & 4 & 3 \\
\hline
\end{tabular}

Tabel 12. Perubahan Rata-rata Skor Pretes dan Postes Kelas Peta Konsep dan Kelas Peta Pikiran pada Konsep Membedakan Koloid, Suspensi Kasar, serta Larutan Sejati Berdasarkan Ciri-Ciri yang Dapat Diamati

\begin{tabular}{|l|c|c|}
\hline \multirow{2}{*}{ Kelas } & \multicolumn{2}{c|}{ Rata-rata nilai } \\
\cline { 2 - 3 } & Pretes & Postes \\
\hline Peta konsep & 52,82 & 84,10 \\
\hline Peta pikiran & 63,33 & 84,02 \\
\hline
\end{tabular}

Tabel 13. Deskripsi Pemahaman dan Skor Jawaban pada Butir Soal 3

\begin{tabular}{|l|c|}
\hline \multicolumn{1}{|c|}{ Deskripsi Pemahaman } & Skor \\
\hline $\begin{array}{l}\text { Tujuan:Siswa dapat:Menuliskan komponen koloid fasa terdispersi dan medium } \\
\text { pendispersi }\end{array}$ & \\
\hline Tidak ada jawaban ataujawaban tidak relevan/salah & 0 \\
\hline Dapat menuliskan satu komponen koloid tanpa penjelasan & 1 \\
\hline Dapat menuliskan dua komponen koloid tanpa penjelasan atau menuliskan satu \\
komponen koloid dengan penjelasan & 2 \\
\hline $\begin{array}{l}\text { Dapatmendiskan duakomponenkoloid tetapi hanya dapat menjelaskan salah satu } \\
\text { komponen koloid }\end{array}$ & 3 \\
\hline Dapat menuliskan dua komponen koloid lengkap dengan penjelasannya & 4 \\
\hline
\end{tabular}

Berdasarkan hasil analisis data pretes dan postes siswa, maka didapatkan perubahan skor jawaban pada butir soal 3 untuk kelas peta konsep dan kelas peta pikiran. Sebaran perubahan skor jawaban disajikan pada Tabel 14. 
Tabel 14. Sebaran Perubahan Skor Jawaban Siswa Pada Pretes dan Postes untuk Kelas Peta Konsep dan Kelas Peta Pikiran

\begin{tabular}{|c|c|c|c|c|}
\hline \multirow{2}{*}{ Skor } & \multicolumn{2}{|c|}{ Pretes } & \multicolumn{2}{c|}{ Postes } \\
\cline { 2 - 5 } & $\begin{array}{c}\text { ISiswa Kelas } \\
\text { Peta Konsep }\end{array}$ & $\begin{array}{c}\text { ¿Siswa Kelas } \\
\text { Peta Pikiran }\end{array}$ & $\begin{array}{c}\text { ¿Siswa Kelas } \\
\text { Peta Konsep }\end{array}$ & $\begin{array}{c}\text { ¿Siswa Kelas } \\
\text { Peta Pikiran }\end{array}$ \\
\hline 0 & 21 & 23 & - & 4 \\
\hline 1 & - & - & - & - \\
\hline 2 & 1 & 3 & 9 & 7 \\
\hline 3 & - & - & 3 & 4 \\
\hline 4 & 4 & - & 14 & 11 \\
\hline
\end{tabular}

Perolehan skor dominan 4 menunjukan bahwa setelah belajar menggunakan peta konsep dan peta pikiran, siswa memiliki pemahaman konsep untuk menjelaskan komponen koloid fasa terdispersi dan medium pendispersi. Jumlah siswa yang mendapatkan skor 4 dari kedua kelas tersebut berbeda.

Tabel 15. Perubahan Rata-rata Skor Pretes dan Postes Kelas Peta Konsep dan Kelas Peta Pikiran pada Konsep Menjelaskan Komponen Koloid Fasa Terdispersi dan Medium Pendispersi

\begin{tabular}{|c|c|c|}
\hline \multirow{2}{*}{ Kelas } & \multicolumn{2}{|c|}{ Rata-rata nilai } \\
\cline { 2 - 3 } & Pretes & Postes \\
\hline Peta konsep & 17,30 & 79,80 \\
\hline Peta pikiran & 5,76 & 66,34 \\
\hline
\end{tabular}

Data tersebut menyimpulkan bahwa pemahaman konsep siswa kelas peta konsep dan kelas peta pikiran pada konsep menjelaskan komponen koloid fasa terdispersi dan medium pendispersi berbeda.

\section{Mengklasifikasikan Jenis Koloid Berdasarkan Fasa Terdispersi dan Medium Pendispersi (Indikator-4)}

Pemahaman konsep siswa dalam mengklasifikasikan jenis koloid berdasarkan fasa terdispersi dan medium pendispersi ditelusuri menggunakan butir soal nomor 4. Jawaban siswa pada butir soal nomor 4 diberikan skor menggunakan rubrik penskoran sebagaimana dideskripsikan pada Tabel 16.

\section{Tabel 16. Deskripsi Pemahaman dan Skor Jawaban pada Butir Soal 4}

\begin{tabular}{|l|c|}
\hline \multicolumn{1}{|c|}{ Deskripsi Pemahaman } & Skor \\
\hline Tujuan l: Siswa dapatmenuliskan nama sistem dispersi & \\
\hline Tidak ada jawaban atau jawaban tidak relevan/salah & 0 \\
\hline Dapat menuliskan satu nama sistem dispersi & 1 \\
\hline Dapat menuliskan dua nama sistem dispersi & 2 \\
\hline Dapat menuliskan tiga nama sistem dispersi & 3 \\
\hline & \\
\hline & \\
\hline & \\
\hline & \\
\hline Tujuan 2 : Siswa dapat menuliskan contoh sistem dispersi & \\
\hline Dapat menuliskan satu contoh sistem dispersi & 0 \\
\hline Dapat menuliskan dua contoh sistem dispersi & 1 \\
\hline Dapat menuliskan tiga contoh sistem dispersi & 2 \\
\hline
\end{tabular}

Berdasarkan hasil analisis data pretes dan postes siswa, maka didapat perubahan skor jawaban pada butir soal 4 untuk kelas peta konsep dan kelas peta pikiran. Sebaran Perubahan skor jawaban disajikan pada Tabel 17. 
Tabel 17. Sebaran Perubahan Skor Jawaban Siswa pada Pretes dan Postes untuk Kelas Peta Konsep dan Kelas Peta Pikiran

\begin{tabular}{|c|c|c|c|c|}
\hline Skor & \multicolumn{2}{|c|}{ Pretes } & \multicolumn{2}{|c|}{ Postes } \\
\hline & $\begin{array}{l}\text { Siswa Kelas } \\
\text { Peta Konsep }\end{array}$ & $\begin{array}{l}\text { ESiswa Kelas } \\
\text { Peta Pikiran }\end{array}$ & $\begin{array}{l}\text { Siswa Kelas } \\
\text { Peta Konsep }\end{array}$ & $\begin{array}{l}\text { ESiswa Kelas } \\
\text { Peta Pikiran }\end{array}$ \\
\hline 0 & 25 & 26 & - & 2 \\
\hline 1 & - & - & 1 & 5 \\
\hline 2 & - & - & 2 & 1 \\
\hline 3 & - & - & 1 & 1 \\
\hline 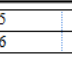 & & \begin{tabular}{r|r} 
& 1 \\
& 12 \\
\end{tabular} & & \\
\hline
\end{tabular}

Perolehan skor dominan 6 menunjukan bahwa setelah belajar menggunakan peta konsep dan peta pikiran, siswa memiliki pemahaman konsep untuk mengklasifikasikan jenis koloid berdasarkan fasa terdispersi dan medium pendispersi. Jumlah siswa yang mendapatkan skor 6 dari kedua kelas tersebut berbeda.

Tabel 18.Perubahan Rata-Rata Skor Pretes dan Postes Kelas Peta Konsep dan Kelas Peta Pikiran pada Konsep Mengklasifikasikan Jenis Koloid Berdasarkan Fasa Terdispersi dan Medium Pendispersi

\begin{tabular}{cccc}
\hline Kelas & \multicolumn{2}{c}{ Rata-rata milai } \\
\cline { 2 - 4 } & Pretes & Postes \\
\hline Peta konsep & 2,56 & 70,51 \\
\hline Peta pikiran & 0 & 07,56 \\
\hline
\end{tabular}

Data tersebut menyimpulkan bahwa pemahaman konsep siswa kelas peta konsep dan kelas peta pikiran pada konsep menjelaskan komponen koloid fasa terdispersi dan medium pendispersi berbeda.

Menjelaskan Sifat-Sifat Koloid (Efek Tyndall, gerak Brown, adsorpsi, koagulasi, elektroforesis, dialisis serta koloid pelindung) (Indikator-5)

Pemahaman konsep siswa dalam menjelaskan sifat-sifat koloid (efek Tyndall, gerak Brown, adsorpsi, koagulasi, elektroforesis, dialisis serta koloid pelindung) ditelusuri menggunakan butir soal nomor 5. Jawaban siswa pada butir soal nomor 5 diberikan skor menggunakan rubrik penskoran sebagaimana dideskripsikan pada Tabel 19.

Berdasarkan hasil analisis data pretes dan postes siswa, maka didapat perubahan skor jawaban pada butir soal 5 untuk kelas peta konsep dan kelas peta pikiran. Sebaran perubahan skor jawaban disajikan pada Tabel 20.

Skor dominan siswa dari kedua kelas tersebut berbeda, sehingga terbukti bahwa pemahaman konsep menjelaskan koloid (efek Tyndall, gerak Brown, adsorpsi, koagulasi, elektroforesis, dialisis serta koloid pelindung) berbeda.

Data tersebut menyimpulkan bahwa pemahaman konsep siswa kelas peta konsep dan kelas peta pikiran pada konsep menjelaskan koloid (efek Tyndall, gerak Brown, adsorpsi, koagulasi, elektroforesis, dialisis serta koloid pelindung) berbeda. 
Tabel 19. Deskripsi Pemahaman dan Skor Jawaban pada Butir Soal 5

\begin{tabular}{|l|c|}
\hline \multicolumn{1}{|c|}{ Deskripsi Pemahaman } & Skor \\
\hline $\begin{array}{l}\text { Tujuan : Siswa dapatmenjelaskan sifat-sifatkoloid (efek Tyndall, gerakBrown, } \\
\text { adsorpsi,koagulasi, elektroforesis, dialisis serta koloid pelindung) }\end{array}$ & 0 \\
\hline \begin{tabular}{l} 
Tidak ada jawaban ataujawaban tidak relevan/salah \\
\hline Dapat menyebutkan satu sifat koloid tanpa penjelasan
\end{tabular} & 1 \\
\hline $\begin{array}{l}\text { Dapatmenyebutkan dua sifat koloid tanpa penjelasan atau satu sifat koloid dengan } \\
\text { penjelasan }\end{array}$ & 2 \\
\hline $\begin{array}{l}\text { Dapatmenyebutkan dua sifat koloid denganperijelasanatau dapat menyebutkan tiga } \\
\text { sifat koloid tanpa penjelasan }\end{array}$ & 3 \\
\hline Dapatmenyebutkan tiga sifat koloidnamm hanya dapatmenjelaskan satu sifat koloid & 4 \\
\hline Dapatmenyebutkan tiga sifat koloidnamm hanya dapatmerijelaskan dua sifat koloid & 5 \\
\hline Dapat menyebutkan tiga sifat koloid dan lengkap dengan penjelasannya & 6 \\
\hline
\end{tabular}

Tabel 20.Sebaran Perubahan Skor Jawaban Siswa pada Pretes dan Postes untuk Kelas Peta Konsep dan Kelas Peta Pikiran

\begin{tabular}{|c|c|c|c|c|}
\hline \multirow{3}{*}{ Skor } & \multicolumn{2}{|c|}{ Pretes } & \multicolumn{2}{c|}{ Postes } \\
\cline { 2 - 5 } & $\begin{array}{c}\text { ESiswa Kelas } \\
\text { Peta Konsep }\end{array}$ & $\begin{array}{c}\text { E Siswa Kelas } \\
\text { Peta Pikiran }\end{array}$ & $\begin{array}{c}\text { ESiswa Kelas } \\
\text { Peta Konsep }\end{array}$ & $\begin{array}{c}\text { E Siswa Kelas } \\
\text { Peta Pikiran }\end{array}$ \\
\hline 0 & 21 & 24 & - & 2 \\
\hline 1 & 1 & - & - & 1 \\
\hline 2 & 4 & - & - & - \\
\hline 3 & - & 2 & - & 13 \\
\hline 4 & - & - & 4 & - \\
\hline 5 & - & - & 3 & 6 \\
\hline 6 & - & - & 19 & \\
\hline
\end{tabular}

Tabel 21.Perubahan Rata-Rata Skor Pretes dan Postes Kelas Peta Konsep dan Kelas Peta Pikiran pada Konsep Menjelaskan Koloid (Efek Tyndall, gerak Brown, adsorpsi, koagulasi, elektroforesis, dialisis serta koloid pelindung)

\begin{tabular}{c|c|c}
\hline \multicolumn{1}{c}{ Kelas } & \multicolumn{2}{c}{ Rata-rata nilai } \\
\cline { 2 - 3 } & Pretes & Postes \\
\hline Peta konsep & 5,76 & 92,94 \\
\hline Peta pikiran & 3,84 & 61,53 \\
\hline
\end{tabular}

Tabel 22. Deskripsi Pemahaman dan Skor Jawaban pada Butir Soal 6

\begin{tabular}{|c|c|}
\hline Deskripsi Pemahaman & Skor \\
\hline \multicolumn{2}{|l|}{ Tujuan : Siswa dapatmenjelaskan proses pembuatankoloid } \\
\hline Tidak ada jawaban atau jawaban tidak relevan/salah & 0 \\
\hline Dapat menjelaskan satu cara pembuatan koloid & 1 \\
\hline $\begin{array}{l}\text { Dapatmerj elaskan dua cara pembuatankoloid atau satu cara pembuatan koloid dan } \\
\text { contoh cara pembuatannya }\end{array}$ & 2 \\
\hline $\begin{array}{l}\text { Dapatmerjelaskan dua cara pembuatan koloid dengan memberikan contoh untuk salah } \\
\text { satu cara pembuatan koloid }\end{array}$ & 3 \\
\hline $\begin{array}{l}\text { Dapatmenjelaskan dua cara pembuatan koloid masing-masing dengan contoh cara } \\
\text { pembuatannya }\end{array}$ & 4 \\
\hline
\end{tabular}




\section{Menjelaskan proses pembuatan koloid (Indikator-6)}

Pemahaman konsep siswa dalam menjelaskan proses pembuatan koloid ditelusuri menggunakan butir soal nomor 6. Jawaban siswa pada butir soal nomor 6 diberikan skor menggunakan rubrik penskoran sebagaimana dideskripsikan pada Tabel 22.

Berdasarkan hasil analisis data pretes dan postes siswa, maka didapatkan perubahan skor jawaban pada butir soal 6 untuk kelas peta konsep dan kelas peta pikiran. Sebaran perubahan skor jawaban disajikan pada Tabel 23.

Tabel 23.Sebaran Perubahan Skor Jawaban Siswa pada Pretes dan Postes untuk Kelas Peta Konsep dan Kelas Peta Pikiran

\begin{tabular}{|c|c|c|c|c|}
\hline \multirow[b]{2}{*}{ Skor } & \multicolumn{2}{|c|}{ Soal Pretes } & \multicolumn{2}{|c|}{ Soal Postes } \\
\hline & $\begin{array}{l}\text { E Siswa Kelas } \\
\text { Peta Konsep }\end{array}$ & $\begin{array}{l}\text { E Siswa Kelas } \\
\text { Peta Pikiran }\end{array}$ & $\begin{array}{l}\text { I Siswa Kelas } \\
\text { Peta Konsep }\end{array}$ & $\begin{array}{l}\text { ESiswa Kelas } \\
\text { Peta Pikiran }\end{array}$ \\
\hline 0 & 26 & 25 & - & 4 \\
\hline 1 & - & - & - & - \\
\hline 2 & - & 1 & 8 & 6 \\
\hline 3 & - & - & 1 & 1 \\
\hline 4 & - & - & 17 & 15 \\
\hline
\end{tabular}

Jumlah siswa yang mendapatkan skor 4 dari kedua kelas tersebut berbeda, sehingga terbukti bahwa pemahaman konsep menjelaskan proses pembuatan koloid antara kelas peta konsep dan peta pikiran berbeda.

Tabel 24. Perubahan Rata-rata Skor Pretes dan Postes Kelas Peta Konsep dan Kelas Peta Pikiran pada Konsep Menjelaskan Proses Pembuatan Koloid

\begin{tabular}{|l|c|c|}
\hline \multirow{2}{*}{ Kelas } & \multicolumn{2}{c|}{ Rata-rata nilai } \\
\cline { 2 - 4 } & Pretes & Postes \\
\hline Peta konsep & 0 & 83,71 \\
\hline Peta pikiran & 1,92 & 66,34 \\
\hline
\end{tabular}

Data tersebut menyimpulkan bahwa pemahaman konsep siswa kelas peta konsep dan kelas peta pikiran pada konsep menjelaskan komponen koloid fasa terdispersi dan medium pendispersi berbeda.

\section{KESIMPULAN}

Terdapat perbedaan pemahaman konsep sistem koloid antara pembelajaran menggunakan peta konsep dengan peta pikiran pada siswa kelas XI MIPA MAN Kota Palangka Raya. Rata-rata nilai postes siswa kelas peta konsep $(85,40 \%)$ lebih tinggi dari pada rata-rata nilai postes kelas peta pikiran $(71,53 \%)$.

\section{SARAN}

Berdasarkan hasil penelitian yang telah dilakukan, maka disarankan bahwa proses pembelajaran dengan menggunakan peta konsep dapat menjadi alternatif bagi guru kimia disekolah dalam mengatasi permasalahan pemahaman yang muncul dalam proses pembelajaran khususnya pada materi sistem koloid atau materi kimia lain yang serupa. 


\section{DAFTAR PUSTAKA}

Arifin, dkk. 2000. Strategi Belajar Mengajar Kimia. Bandung: Universitas Pendidikan Indonesia.

Dahar, R. W. 1989. Teori-Teori Belajar. Jakarta: Erlangga.

Dahar, R. W. 2011. Teori-Teori Belajar. Jakarta: Erlangga.

Dalina, S.M. 2015. Pemahaman Konsep Koloid Setelah Pembelajaran Menggunakan Model Kooperatif CIRC (Cooperative Integrated Reading And Composition) Siswa Kelas XI-IPA SMA-6 Palangka Raya Tahun Ajaran 2014/2015.Skripsi Sarjana, tidak dipublikasikan, Universitas Palangka Raya.

Daryanto, R. T. 2015. Teori Belajar dan Proses Pembelajaran yang Mendidik. Yogyakarta: Gava Media.

Dimyati \& Mudjiono. 2009. Belajar dan Pembelajaran. Jakarta : Rineka Cipta.

Dwi, K. H. 2014. Pengembangan Kerangka Kerja TPACK pada Materi Koloid untuk Meningkatkan Aktivitas Pembelajaran dalam Mencapai HOTS Siswa. Jurnal Penelitian Kimia, 3 (1): 2068-2074.

Hamalik, O. 2001. Proses Belajar Mengajar. Jakarta: PT Bumi Aksara.

Hamalik, O. 2005. Proses Belajar Mengajar. Jakarta: PT Bumi Aksara.

Herlie. 2016. Pemahaman Konsep Koloid Hasil Pembelajaran Melalui Pembuatan Peta Konsep Pada Siswa XI IPA-2 SMA Negeri 4 Palangka Raya Tahun Ajaran 2015/2016. Skripsi Sarjana, tidak dipublikasikan, Universitas Palangka Raya.

Kaharapen, A. 2015. Pemahaman Konsep Sistem Koloid Pasca Pembelajaran Menggunakan Strategi Belajar Mind Mapping Pada Siswa Kelas XI IPA-2 MAN Model Palangka Raya Tahun Ajaran 2014/2015. Skripsi Sarjana, tidak dipublikasikan, Universitas Palangka Raya.

Latief, dkk. 2014. Pengaruh Pembelajaran Kontekstual Terhadap Hasil Belajar. Jurnal Penelitian Matematika.

Permata, T. P., dkk. 2017. Efektivitas Media Mind Map Berbasis Metode Latihan Berjenjang Terhadap Hasil Dan Retensi Belajar Siswa Pada Materi Konsep Mol Di Kelas X SMA Negeri 8 Pontianak. Jurnal Penelitian Ilmiah.

Raharjo, S. 2017. SPSS Indonesia. [Online]. http//www.spssindonesia.com [diakses pada 5 juni 2019]

Sudjana. 2005. Metode Statistik. Bandung: Pustaka Tarsito

Sugiyono. 2011. Metode Penelitian Pendidikan (Pendekatan Kuantitatif, Kualitatif, dan $R \& D$ ). Bandung: Alfabeta.

Suyanti, R. D. 2010. Strategi Pembelajaran Kimia Edisi Pertama. Yogyakarta: Graha Ilmu.

Tim Penyusun. 2017. Pedoman Penulisan Skripsi. Palangka Raya: Universitas Palangka Raya.

Trianto. 2010. Model Pembelajaran Terpadu. Jakarta: Bumi Aksara.

Widhiarso, W. 2012. Uji Homogenitas Data. [Online]. http://widhiarso.staff.ugm.ac.id [diakses 17 juli 2019]

Sari, A.Q. 2017. Batasan Prasyarat Uji Normalitas Dan Uji Homogenitas Pada Model Regresi Linear. Jurnal Penelitian Matematika. 